\title{
Actual Evapotranspiration in Suli Alpine Meadow in Northeastern Edge of Qinghai-Tibet Plateau, China
}

\author{
Jin-kui Wu, ${ }^{1}$ Shi-qiang Zhang, ${ }^{1,2}$ Hao Wu, ${ }^{1,3}$ Shi-wei Liu, ${ }^{1}$ Yu Qin, ${ }^{1}$ and Jia Qin ${ }^{1}$ \\ ${ }^{1}$ State Key Laboratory of Cryospheric Science, Cold and Arid Regions Environmental and Engineering Research Institute, \\ Chinese Academy of Sciences, Lanzhou, Gansu 730000, China \\ ${ }^{2}$ College of Urban and Environmental Sciences, Northwest University, Xi'an, Shannxi 710127, China \\ ${ }^{3}$ Yunnan Hydraulic Research Institute, Kunming, Yunnan 650228, China
}

Correspondence should be addressed to Jin-kui Wu; jkwu@lzb.ac.cn

Received 12 December 2014; Revised 7 April 2015; Accepted 22 April 2015

Academic Editor: Monique Leclerc

Copyright (C) 2015 Jin-kui Wu et al. This is an open access article distributed under the Creative Commons Attribution License, which permits unrestricted use, distribution, and reproduction in any medium, provided the original work is properly cited.

Actual evapotranspiration was observed by using eddy covariance (EC) technique, calculated by micrometeorological method the Bowen ratio energy balance (BREB) and measured by micro-lysimeter (ML) in the Suli alpine meadow which located in the northeastern edge of Qinghai-Tibet Plateau noted for its high elevation and cold environment during the growing season in 2011. Results showed that the energy balance ratio for half-hour data was 0.74 . Without consideration of uncertainty, the evapotranspiration values estimated by BREB, ML, and EC were $270.6 \mathrm{~mm}, 238.9 \mathrm{~mm}$, and $236.1 \mathrm{~mm}$, respectively. Significant correlation existed between the evapotranspiration results by the three methods. Uncertainties of the evapotranspiration estimation by BREB, ML, and EC were $19.6 \mathrm{~mm}, 15.6 \mathrm{~mm}$, and $15.1 \mathrm{~mm}$, respectively. Deduced by facts on the natural and vegetation conditions, the value of evapotranspiration should be equal to that of precipitation, that is, about $252 \mathrm{~mm}$. From this point, the evapotranspiration values estimated by the three methods were within a reliable range. The EC method has larger advantage and wider scope for the estimation of evapotranspiration in alpine meadow area.

\section{Introduction}

Evapotranspiration is one of the major components in the hydrological cycle and an important factor that affects regional water balance and ecosystems [1]. Meanwhile, it is the main form of water consumption in the earth system. Nearly $70 \%$ of the precipitation returns into the atmosphere through evapotranspiration and this ratio is up to $90 \%$ in arid region [2,3]. Furthermore, evapotranspiration is an important boundary condition in climate modeling and weather prediction, as it is an important mechanism in the generation of precipitation [4]. Land surface evapotranspiration is closely related to the atmospheric environment, soil environment, and plant ecological and physiological processes. In climatology, agriculture, and above all in hydrology, the calculation of the real evapotranspiration may quantify the climatic water deficit and analyze the aridity of a given environment in detail [5]. Additionally, it enables hydrologists and resources managers to evaluate water balance at different space and time scales and to define the water reservoir available in a given area for different water uses [6]. Also, its reliable estimation is essential to water resource planning and management [7].

There is a great variety of methods for measuring/ estimating ET, such as weighting lysimeters, Bowen ratio energy balance (BREB), eddy covariance (EC), aerodynamic method, remote sensing method, hydrological model, and crop coefficient approach.

Weighting lysimeters, measuring evapotranspiration directly through changes in mass, are the most convenient way to quantify evapotranspiration [8]. Such manual lysimeters have been used to determine periodic water use for a variety of plants grown in small containers [9]. By using a large-scale weighing lysimeter, daily evapotranspiration 
of irrigated winter wheat and maize was determined for five seasons between 1995 and 2000 at Luancheng Station in the North China Plain [10]. McKeon et al. [11] developed a hand truck with a load cell for manual measurements of single containers up to $250 \mathrm{~kg}$. Owen et al. [12] automated the process for small containers by connecting top loading balances to a data logger in a nursery setting. Manual lysimeters were also used to measure daily evapotranspiration and evaluate the Penman-Monteith equation at the plateau wetlands in the eastern edge of Qinghai-Tibet Plateau [13].

The two most frequently used methods for estimating the actual evapotranspiration indirectly are the Bowen ratio energy balance (BREB) and the eddy correlation (EC) techniques [14]. BREB-based evapotranspiration rates can be obtained independently of weather conditions. However, any inaccuracy in one of the instruments will have a direct influence on all measured fluxes. Further, the method does not work under Bowen ratio values in the vicinity of -1 . Furthermore, the BREB method is based on the assumption of equal eddy diffusivities for heat and water vapor, conditions which are not always met [15]. On the other hand, in the EC method no assumptions concerning the eddy diffusivities need to be made. The disadvantages of the EC method are dew formation on the instruments during daybreak, which renders the instruments unreliable, and further the fact that the instruments do not work properly under precipitation [14].

Both the BREB and EC methods have been intercompared in a number of field studies. Using four BREB systems and three EC systems in an agricultural field, Dugas et al. [16] found that the sum of EC-based latent and sensible heat fluxes was lower than the BREB-based quantities, with the latent heat flux showing the highest differences. Using both methods in a semiarid environment, Unland et al. [17] indicated that the BREB method is the more adequate method to obtain long records of surface fluxes, basically because EC instruments require more maintenance, but that the EC method is likely to have a higher accuracy over short periods. For grassland and forested areas, Twine et al. [18] gave an overview of the studies in which the BREB and the EC methods have been intercompared. These studies generally show, consistent with the previously mentioned studies over grasslands and agricultural fields, an underestimation of the sum of the EC-based latent and sensible heat fluxes, as compared to the available energy.

Qinghai-Tibet Plateau (QTP) is a vast elevated plateau in Central Asia or East Asia, covering most of the Tibet Autonomous Region and Qinghai Province in western China. With an average elevation exceeding $4500 \mathrm{~m}$ and an area of $2500000 \mathrm{~km}^{2}$, the QTP is the world's highest and largest plateau. The QTP is the headwaters of the drainage basins of most of the streams in surrounding regions. The impact of global climate change on the QTP is of intense scientific interest [19]. Comparing to other regions at the same latitude, the atmospheric layer in QTP is thinner and cleaner and has less water vapor and dust. It leads to higher atmospheric transparency and stronger direct solar radiation [20]. In the context of strong radiation, the regional ecosystem also is exposed to low temperature environment. In addition, the precipitation usually concentrates in May to September, the growing season for plants. Under this unique ecological environment, the evapotranspiration of alpine meadow ecosystem shows its particularity [21].

In this paper, we chose an observation site located in the northeastern edge of the QTP for actual evapotranspiration study. The objectives were to (1) obtain the actual evapotranspiration of the alpine meadow by using different methods, (2) investigate the energy balance rate (EBR), (3) estimate the uncertainty of the evapotranspiration estimation, and (4) compare the results of the actual evapotranspiration from different methods and determine a better one for future observation.

\section{Site Description and Measurements}

2.1. Site Description. Field measurements were conducted at the Suli Ecological and Environmental Station $\left(38^{\circ} 25^{\prime} \mathrm{N}\right.$, $98^{\circ} 19^{\prime} \mathrm{E} ; 3885 \mathrm{~m}$ a.s.1.), Cold and Arid Regions Environmental and Engineering Research Institute, Chinese Academy of Science. The research station is located in a large valley oriented southeast-northwest and surrounded by the Qilian Mountains, the northeastern edge of the QTP. The average altitude of the mountains is $4200 \mathrm{~m}$ and of the valley is $2500-$ $4100 \mathrm{~m}$. The Shulehe River passes to the study area.

The study area belongs to the continental arid desert climate region [22]. It has low average annual temperature, little rainfall, and high evaporation. The mean annual temperature was approximately $-5^{\circ} \mathrm{C}$ and the annual precipitation ranged from 100 to $300 \mathrm{~mm}$ [23]. In the growing season of May through September, the plentiful sunshine and rainfall $(80 \%$ of annual total precipitation) allow plants to grow efficiently.

The landscape is characterized by large mountain ranges with steep valleys and gorges interspersed with relatively level and wide intermountain grassland basins [24]. Our observation tower is set up in a large valley basin. It provides a sufficient upwind fetch of uniform land cover for measuring mass and energy fluxes using tower-based eddy covariance systems.

According to the Chinese soil classification system, the main soil types in this area are frigid calcic soils (Chernozems, Kastanozems) and bog soils (gleysols, histosols, gelic gleysols, gelic histosols, umbric cambisols) [23]. The surface 0.05$0.10 \mathrm{~m}$ horizons of the observation site, which are classified as Mat Cry-gelic Cambisols, are wet and high in organic matter.

The study area is in an alpine meadow. The plant community is dominated mainly by Carex moocroftii and Kobresia pygmaea $[25,26]$. The plants start to grow in May, when the air temperature starts rising, and reach maximum aboveground biomass in July and August, when the air temperature and precipitation are in the highest of the year. Their aboveground parts die in October. During the growing season, the plants accumulate photosynthates in belowground storage organs in preparation for the next spring $[25,26]$. The study site is grazed by yaks and sheep every winter. 


\subsection{Measurements}

2.2.1. Flux Measurements. The experimental site was equipped with an eddy covariance (EC) system to measure energy, water, and $\mathrm{CO}_{2}$ fluxes. The $\mathrm{EC}$ system was installed at a height of $3.0 \mathrm{~m}$, including a 3D ultrasonic anemometerthermometer (CSAT-3, Campbell Scientific Inc., Logan, UT, USA) and an open-path infrared gas $\left(\mathrm{CO}_{2} / \mathrm{H}_{2} \mathrm{O}\right)$ analyzer (IRGA) (LI-7500, LI-COR Inc., Lincoln, NE, USA). The signals were recorded at $10 \mathrm{~Hz}$ by a data logger (CR3000, Campbell Scientific Inc., Logan, UT, USA).

2.2.2. Meteorological Measurements. A $10 \mathrm{~m}$ tall meteorological tower was established in 2008. A four-component net radiometer (CNR-1, Kipp \& Zonen, Delft, Netherlands) was set up at the height of $2.0 \mathrm{~m}$ above the ground. Air temperature $\left(T_{a}\right)$ and relative humidity $(\mathrm{RH})$ were measured at four levels $(2.0 \mathrm{~m}, 5.0 \mathrm{~m}, 7.5 \mathrm{~m}$, and $10.0 \mathrm{~m})$ (HMP 45C, Vaisala, Helsinki, Finland). A wind set sensor (020C-1, Met One Inc., OR, USA) was set up at the same four heights to measure horizontal wind speed and wind direction. The data of $T_{a}, \mathrm{RH}$, and $W_{s}$ at the height of $2.0 \mathrm{~m}$ and $10.0 \mathrm{~m}$ above the ground were adopted in this study.

The soil temperature $\left(T_{s}\right)$ profile was measured at six depths $(0.05,0.10,0.30,0.50$, and $0.70 \mathrm{~m})$ by thermistors (107L, Campbell Scientific Inc., Logan, UT, USA). Soil water content (SWC) profile was measured at five depths $(0.10$, $0.20,0.40,0.60$, and $0.80 \mathrm{~m}$ ) by time domain reflectometry probes (EnviroSMART, Campbell Scientific Inc., Logan, UT, USA). Soil heat flux was measured by two soil heat flux plates (HFP01, Hukseflux Inc., Delft, Netherlands) in separate locations at $0.05 \mathrm{~m}$ and $0.10 \mathrm{~m}$ below the soil surface. Precipitation was measured using an all-weather precipitation gauge (Geonor T-200B, Norway) without heating above the canopy. All meteorological data was recorded every $2 \mathrm{~s}$, and halfhourly mean data were logged by the data logger (CR1000, Campbell Scientific Inc., Logan, UT, USA).

2.2.3. Micro-Lysimeter. The cylindrical shaped microlysimeter was made of metal by $2 \mathrm{~mm}$ thick. It was divided into inner barrel and the outer barrel. The inner barrel of each micro-lysimeter, containing isolated volumes of soil and grass mounted flush with or slightly above the soil surface, is $36 \mathrm{~cm}$ in diameter with a depth of $40 \mathrm{~cm}$. The micro-lysimeters were weighed twice a day to determine water loss using electronic balances with $0.001 \mathrm{~kg}$ precision to meet the measurement requirements. We installed three micro-lysimeters within the study meadow at random.

\section{Methods and Data}

3.1. Eddy Covariance (EC) Technique. According to the principle of eddy covariance technique, sensible heat flux $(H)$ and latent heat flux $(\lambda E)$ were calculated by the following formula:

$$
\begin{array}{r}
H=\rho_{a} c_{p} \overline{w^{\prime} \theta^{\prime}}, \\
\lambda E=\lambda \rho_{a} \overline{w^{\prime} q^{\prime}},
\end{array}
$$

where $\rho_{a}$ is air density $\left(\mathrm{kg} \mathrm{m}^{-3}\right)$ at a given air temperature, $c_{p}$ is the air specific heat $\left(\mathrm{J} \mathrm{kg}^{-1} \mathrm{~K}^{-1}\right), \lambda$ is the latent heat of vaporization $\left(\mathrm{J} \mathrm{kg}^{-1}\right), w^{\prime}, \theta^{\prime}$, and $q^{\prime}$ denote fluctuations of vertical wind speed $\left(\mathrm{m} \mathrm{s}^{-1}\right)$, air temperature $(\mathrm{K})$, and specific humidity $\left(\mathrm{kg} \mathrm{kg}^{-1}\right)$, respectively, and over bars indicate average over the sampling interval (30 min in this study). Positive scalar fluxes denote the energy transfer from the canopy surface to the atmosphere while negative fluxes signify the reverse.

Software EdiRe was chosen for data correction and quality control in this study. Data processing is mainly referenced by the EC data processing method recommended by FLUX NET [27]. Before the scalar flux computation, spike detection and removal and coordinate rotation were performed. Coordinate rotation was performed to reorient the $X$-axis parallel to the local main wind direction and to force the mean vertical velocity to zero. In addition, the sonic temperature fluctuations were taken into account to correct the fluxes of sensible heat, and the Webb-Pearman-Leuning (WPL) method was used to correct latent heat fluxes from fluctuations in temperature and water vapor density.

The available data sets were screened to remove any anomalous half-hourly fluxes that resulted from malfunction of the sensors following the criteria: (1) incomplete halfhourly measurement, mainly caused by mechanical conditions such as power failure or infrared gas analyzers (IRGA) calibration, (2) precipitation events, and (3) outliers due to occasional spike in half-hourly flux values for unknown reasons [28].

Roughly $18 \%$ of the data obtained from the EC system were discarded in the growing season of 2011, which introduced data gaps. These gaps were filled following the strategies put forward by Falge et al. [29]: (1) linear interpolation was used to fill the gaps that were less than $2 \mathrm{~h}$ by calculating an average of the values immediately before and after the data gap; (2) other data gaps were filled using the empirical relationships (look-up tables method); that is, the bin-average values for $\lambda E$ or $H$ in connection with their environmental drivers such as atmospheric vapor pressure deficit (VPD), in cases where those relationships could be established, with three bimonthly look-up tables, were created for the growing season of 2011; and (3) if these relationships could not be established due to missing meteorological data, mean daily variations in the fluxes were used to fill the gaps.

3.2. Bowen Ratio Energy Balance (BREB) Method. The Bowen ratio $\beta$ can be calculated as

$$
\beta=\frac{H}{\lambda E}
$$

We can approximately express $\beta$ as

$$
\beta=\gamma \frac{T_{1}-T_{2}}{e_{1}-e_{2}}=\gamma \frac{\Delta T}{\Delta e}
$$

with $\gamma$ being the psychometric constant $\left(\mathrm{kPa}^{\circ} \mathrm{C}^{-1}\right), T_{1}$ and $T_{2}$ being the air temperatures $\left({ }^{\circ} \mathrm{C}\right)$ at levels 1 ( $2 \mathrm{~m}$ in height) and 2 (10.0 $\mathrm{m}$ in height), respectively, and $e_{1}$ and $e_{2}$ being the 
water vapor pressures $(\mathrm{kPa})$ at levels 1 and 2 , respectively. The psychrometric constant is calculated as

$$
\gamma=0.665 \times 10^{-3} \mathrm{P}
$$

with $P$ being the atmospheric pressure $(\mathrm{kPa})$. Using the net radiation $\left(R_{n}, \mathrm{~W} \mathrm{~m}^{-2}\right)$ and the observed ground heat flux $(G$, $\mathrm{W} \mathrm{m}^{-2}$ ), the sensible and latent heat flux can be calculated as

$$
\begin{aligned}
H & =\frac{\beta\left(R_{n}-G\right)}{1+\beta}, \\
\lambda E & =\frac{R_{n}-G}{1+\beta} .
\end{aligned}
$$

The ground heat flux at the soil surface $(G)$ was calculated from measurements of the soil heat flux plates by taking into account the energy storage above the plates, which can be estimated using the soil water content and the fluctuations in the soil temperature. In this study, we used two methods as follows.

(1) Using the soil heat flux measured by the soil heat flux plate at the depth of $0.05 \mathrm{~m}$ and soil water content at the depth of $0.20 \mathrm{~m}$ [30],

$$
G=G_{5}+C \int_{0}^{z} \frac{\partial T}{\partial t} d z
$$

where $G$ is surface soil heat flux $\left(\mathrm{W} \mathrm{m}^{-2}\right)$; $G_{5}$ is the soil heat flux plate at the depth of $0.05 \mathrm{~m}\left(\mathrm{~W} \mathrm{~m}^{-2}\right)$; $C$ is the soil heat capacity $\left(\mathrm{J} \mathrm{m}^{-3}{ }^{\circ} \mathrm{C}^{-1}\right) ; T$ is temperature of the soil above the plates $\left({ }^{\circ} \mathrm{C}\right)$.

(2) Using the soil heat flux measured by the soil heat flux plate at the depth of $0.10 \mathrm{~m}$, surface temperature, ground temperatures at the depth of $0.05 \mathrm{~m}$ and $0.10 \mathrm{~m}$, and soil water

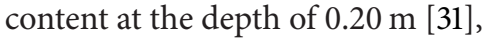

$$
\begin{aligned}
G= & G_{10} \\
& +C\left(0.01 \times \frac{\partial T_{s}}{\partial t}+0.06 \times \frac{\partial T_{5}}{\partial t}+0.03 \times \frac{\partial T_{10}}{\partial t}\right),
\end{aligned}
$$

where $G$ is surface soil heat flux $\left(\mathrm{W} \mathrm{m}^{-2}\right) ; G_{10}$ is the soil heat flux plate at the depth of $0.10 \mathrm{~m}\left(\mathrm{~W} \mathrm{~m}^{-2}\right) ; C$ is the soil heat capacity $\left(\mathrm{J} \mathrm{m}^{-3}{ }^{\circ} \mathrm{C}^{-1}\right) ; T_{s}, T_{5}$, and $T_{10}$ are ground temperature at the depth of surface of $0.05 \mathrm{~m}$ and $0.10 \mathrm{~m}\left({ }^{\circ} \mathrm{C}\right)$.

Since the BREB method results in unreliable estimates of the turbulent fluxes when $\beta$ approaches -1 , data were excluded for Bowen ratios between -0.7 and -1.3 [14]. Further, according to Andreas and Cash [32], data for Bowen ratios larger than 10 or lower than -0.7 (this partly excludes data that were already excluded by the first restriction) and negative or zero vapor pressure gradients were eliminated from the analysis. Overall, $91 \%$ of the BREB-based latent heat flux estimates were deemed fit for analysis.

3.3. Micro-Lysimeter (ML) Method. According to the principle of water balance in a lysimeter, the formula for calculating evapotranspiration is as follows:

$$
\Delta S=P+W-Q-R-\mathrm{ET},
$$

where $\Delta S$ is the soil water variation within a lysimeter; $P$ is for precipitation; $W$ is net upward flux of the lower boundary of the soil; $Q$ is for leakage; $R$ is for surface runoff and ET is for evapotranspiration. Units for all variables are in $\mathrm{mm}$.

In this study, the precipitation was directly measured by T200B; the leakage from the lower part of lysimeter was measured by the containers. Considering the fact that the determination depth was less than the water table, the effect of recharge from groundwater was not considered, namely, $W=0$, in this equation. According to the observations, no leakage occurred during the study period. Due to the small precipitation intensity and flat topography, no runoff generated; thus $R$ was ignored. While no precipitation occurs, the above equation can be expressed as

$$
E=\Delta S,
$$

where $\Delta S$ was calculated directly through changes in mass in $\mathrm{mm}$. The mean values of the 3 micro-lysimeters are used for analysis.

3.4. The Energy Balance Ratio (EBR). The net radiation $\left(R_{n}\right)$ is partitioned into sensible $(H)$, latent $(\lambda E)$, and soil $(G)$ heat fluxes:

$$
R_{n}=H+\lambda E+G .
$$

The energy balance ratio (EBR) was used to assess the performance of the EC system [33]. EBR is calculated using the following equation for half-hourly periods where all the data $\left(R_{n}, H, \lambda E\right.$, and $\left.G\right)$ were available [33]:

$$
\mathrm{EBR}=\frac{\sum(\lambda E+H)}{\sum\left(R_{n}-G\right)},
$$

where the turbulent energy flux $(\lambda E+H)$ is the results from EC method and available energy flux $\left(R_{n}-G\right)$ is from the BREB. The advantage of this method is that it gives an overall evaluation of energy balance closure at longer time scales by averaging over random errors in the half-hour measurements [33].

3.5. The Atmospheric Stability (AS). The atmospheric stability (AS) describes the state of the atmospheric turbulence. Usually it is represented by Richard number [34, 35],

$$
\mathrm{Ri}=\frac{g * \partial \theta / \partial z}{T *(\partial u / \partial z)^{2}}
$$

where $g$ is acceleration of gravity, $9.8 \mathrm{~m} \mathrm{~s}^{-2}$; $T$ is the mean absolute temperature of two layers $(\mathrm{K}) ; \theta$ is potential temperature $(\mathrm{K}) ; u$ is the wind speed $\left(\mathrm{m} \mathrm{s}^{-1}\right) ; z$ is the height from the surface $(\mathrm{m})$.

In this study, the two gradient layers used for analyzing were 2 and $10 \mathrm{~m}$ as BREB did.

\section{Results}

4.1. Soil Heat Flux (G). Figure 1 showed the relationship between calculated results of soil heat flux $(G)$ by two 


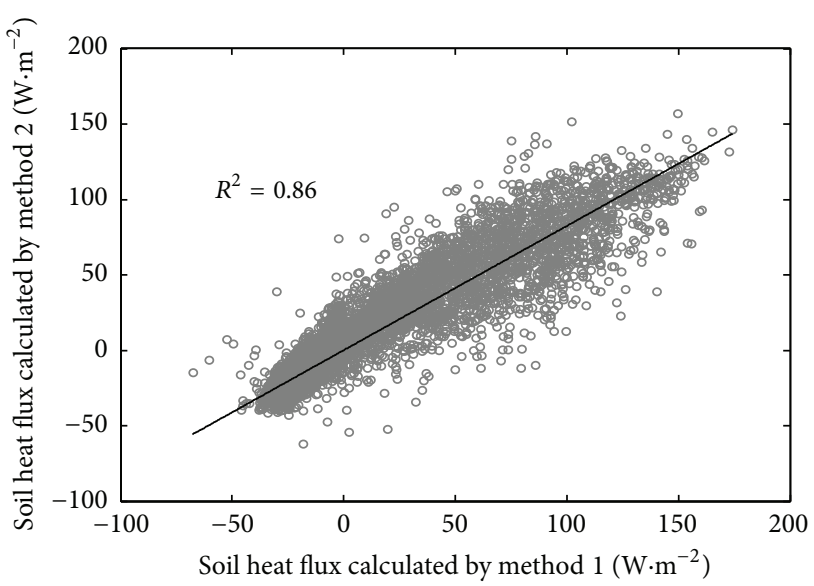

FIGURE 1: The relationship between calculated soil heat fluxes by two methods.

methods by using 30-minute data. As seen from the figure, two scenarios of $G$ had a good agreement with a correlation coefficient of 0.93 (Figure 1) and root mean square error (RMSE) of $16 \mathrm{~W} \mathrm{~m}^{-2}$. Based on this, the average values of $G$ by 2 methods were used for the following calculations.

4.2. The Energy Balance Ratio (EBR). The EBR for all 30minute data is 0.74 for the growing season of 2011, falling in the median regions of the reported energy closure, which range from 0.55 to 0.99 for FLUXNET [33] (Figure 2(a)).

During the observational period, daily latent heat flux, daily sensible flux, and daily turbulent energy flux were $71 \mathrm{~W} \mathrm{~m}^{-2}, 30 \mathrm{~W} \mathrm{~m}^{-2}$, and $101 \mathrm{~W} \mathrm{~m}^{-2}$, respectively, while the daily net radiation, daily soil heat flux, and available energy were $132 \mathrm{~W} \mathrm{~m}^{-2}, 12 \mathrm{~W} \mathrm{~m}^{-2}$, and $120 \mathrm{~W} \mathrm{~m}^{-2}$, respectively. The turbulent flux by eddy covariance system was less than the available energy by BREB method (Figure 2(b)). The energy balance ratio for daily data was 0.84 .

Monthly EBRs were obtained by using observational 30minute data from May to September 2011. The regression slopes were $0.76,0.72,0.75,0.73$, and 0.73 for May, June, July, August, and September, respectively.

4.3. Diurnal Change of Atmospheric Stability. The analysis results of diurnal change atmospheric stability $(\zeta)$ at the observation site from May to September 2011 showed the following: during nighttime, $\zeta>0$, the value of AS varied between 0.2 and 0.3 , atmospheric stratification was stable, and the development of turbulence was suppressed, while during daytime, $\zeta<0$, the atmospheric stratification was unstable, the maximum degree of atmospheric instability occurred around noon $(\zeta=-2.9)$, and the turbulent exchange was full; at sunrise (7:00 8:00) and sunset (19:00 20:00) periods, the atmospheric stratification was nearly neutral, namely, $\zeta \approx 0$, and atmospheric stratification was at the transition period from being stable to unstable or unstable to a stable.

4.4. Daily Evapotranspiration Determined by the 3 Methods. Because the observation period of micro-lysimeter was between 19/6/2011 and 13/9/2011, we had to choose this period for the comparative study of evapotranspiration.

The daily evapotranspiration determined by 3 methods had similar variation trends (Figure 3). Daily evapotranspiration had good relationship with the air temperature as shown in Figure 3. Also, sharp increase of daily evapotranspiration usually connected to relative heavier precipitation (Figure 3). It could be explained that more sufficient water was supplied for evapotranspiration.

Under no consideration of uncertainty, the cumulative evapotranspiration estimated by BREB method was $270.6 \mathrm{~mm}, 13 \%$ higher than that measured by ML method and $15 \%$ higher than that estimated by EC method. The cumulative evapotranspiration was $238.9 \mathrm{~mm}$ by ML method, nearly the same as $236.1 \mathrm{~mm}$ calculated by EC method.

\section{Discussion}

5.1. The Energy Balance. As this study showed, the EBR at the study site was 0.74 . It indicated that the energy was not entirely closed by the results from the eddy covariance method and the energy balance method. In fact, this phenomenon existed in many eddy covariance measurements. By using the flux data across 22 sites and 50 site-years in FLUXNET, a network of eddy covariance sites measuring long-term carbon and energy fluxes in contrasting ecosystems and climates, Wilson et al. [33] found a general inclosure at most sites existing, with a mean imbalance in the order of $20 \%$. Franssen et al. [34, 35] and Li et al. [36] reported their results based on 26 sites (of which 5 were cropland/grassland sites) in Europe and 8 sites (of which 3 were grassland sites) in China, respectively. Both of the analysis results showed that no full energy closure existed in those observational sites. The observation results in alpine meadow in QTP [37-39] also indicted that turbulent energy flux usually was lower than the available energy flux. During the growing season, the latent heat flux was the main part of the turbulent flux. The underestimation of turbulent flux thus led to underestimation of evapotranspiration in those areas.

Li et al. [39] gave a detailed analysis on the causes of inclosure of energy balance from the deviations in samples and instruments, the loss of high frequency and low frequency, the ignorance of some energy items, and loss of advection.

Infrared gas analyzers (IRGA) are widely used around the world for measuring flux exchange of terrestrial ecosystems. However, further comparisons have revealed substantial differences between open- and closed-path designs, especially in cold environments, causing concern in the flux research community [40]. Specifically, carbon dioxide and water vapor density measurements from an open-path IRGA may be biased when the instrument significantly heats the air that it measures, particularly in cold environments [41].

Considering the fact that the study site is in a cold region, the self-heating correction on the sensible and latent heat flux by the LI-7500 open-path is needed. Burba et al. proposed corrections requiring no complementary closedpath measurements, introducing new sensible heat flux terms estimated theoretically and verified experimentally [41]. In 


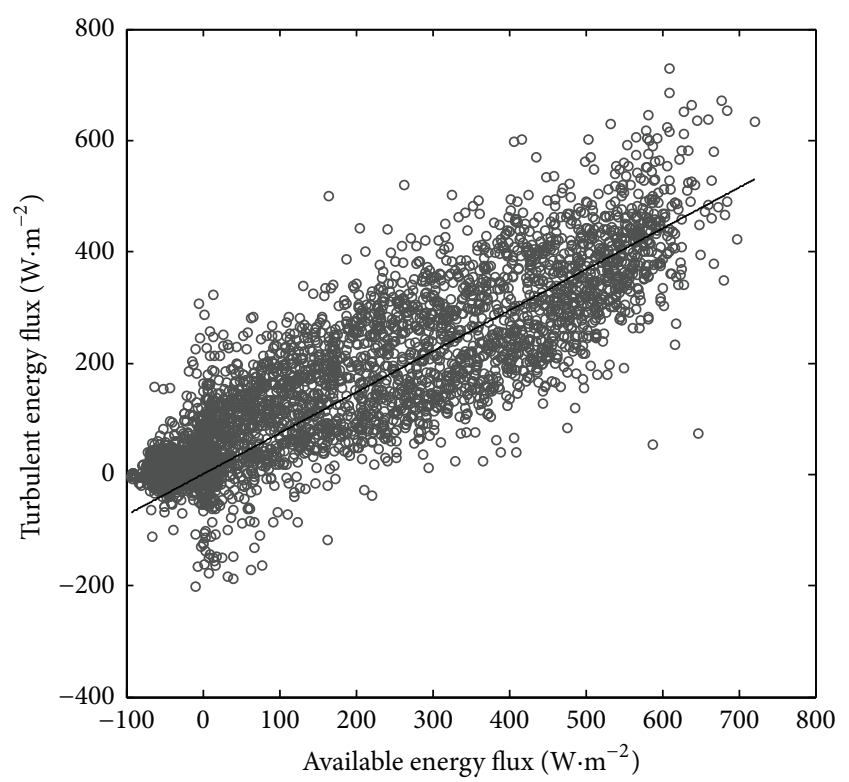

(a)

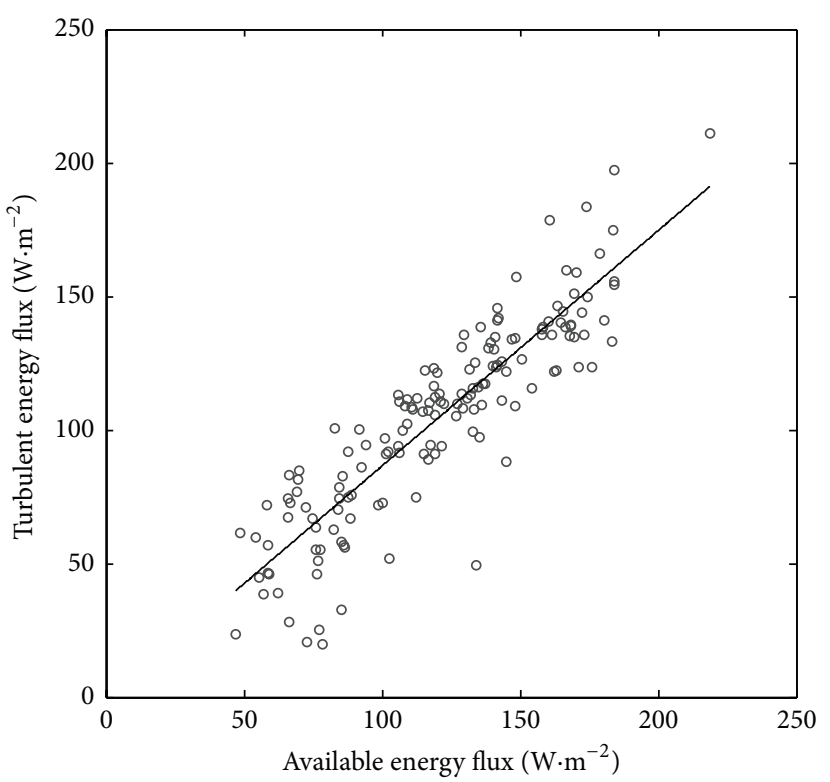

(b)

FIGURE 2: Relationship between the turbulent energy flux and available energy flux ((a) 30-minute data; (b) daily data).

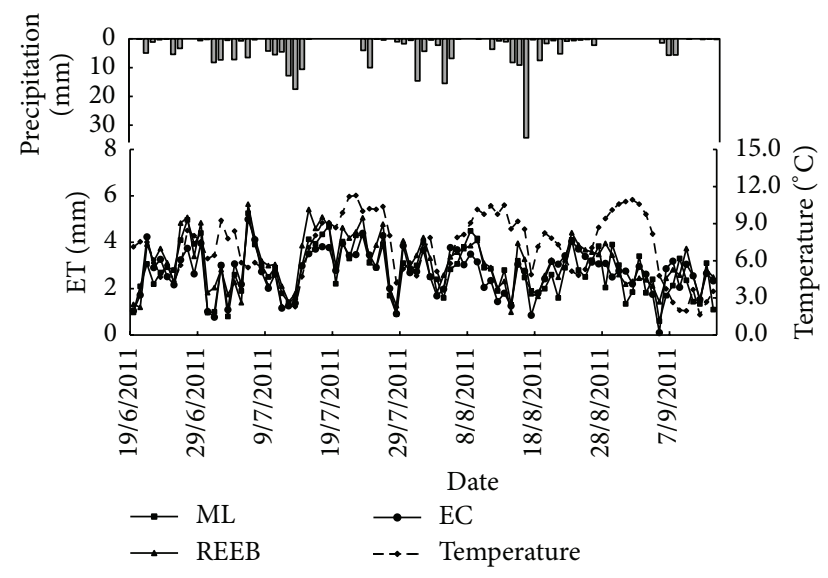

FIGURE 3: Daily variation of air temperature, precipitation, and evapotranspiration (ET) estimated by three methods during the observation period.

this study, we followed this correction method and the parameters for the calculation were derived from Burba et al. [41] and Ji et al. [42].

By using half-hour data, the correction results showed that the mean sensible heat flux correction was $13 \mathrm{~W} \mathrm{~m}^{-2}$, exceeding the uncorrected mean sensible heat flux by up to 43.3\%. The heat exchanges from the bottom window and spars were the main contributor of the correction term of sensible heat flux inside the path with the mean value of $9.5 \mathrm{~W} \mathrm{~m}^{-2}$ and $3.5 \mathrm{~W} \mathrm{~m}^{-2}$, respectively. Ji et al. [42] reported their results in the Heihe River basin, a neighboring river basin of the Shule River basin, where the mean sensible heat flux correction was about $9 \mathrm{~W} \mathrm{~m}^{-2}$. Burba et al. [41] found high-frequency temperature measurements inside the path producing sensible heat flux inside the instrument path exceeding the ambient heat flux by up to $14 \%$. As our study site was colder than other sites, the extent of the correction was larger.

For latent heat flux, the mean correction value was only about $1 \mathrm{~W} \mathrm{~m}^{-2}$ and exceeded the uncorrected mean latent heat flux by up to $1.4 \%$. The magnitude of the correction term was small and negligible. Similar results were found in Burba et al. [41] and Ji et al. [42]. The former reported that the daily correction values of latent heat flux were $-0.14 \sim 0.47 \mathrm{~W} \mathrm{~m}^{-2}$ and the latter reported a daily correction value of $0.47 \mathrm{~W} \mathrm{~m}^{-2}$.

5.2. The Comparison of Evapotranspiration Estimated by 3 Methods under No Consideration of Uncertainty. Linear regression analysis was made to determine the relationship between the results of evapotranspiration by eddy covariance method, micro-lysimeter method, and Bowen ratio energy balance method (Figure 4). Generally speaking, the estimated results from 3 methods were in a good agreement.

Though the cumulative evapotranspiration by EC method was very close to that by ML method during the whole observational period as mentioned above, the daily variation of evapotranspiration was not entirely consistent (Figure 3) and had the worst correlation (Figure 4). The daily evapotranspiration measured by micro-lysimeters had a wider fluctuation range due to the measurement errors from the manual weighting. The weighting results were always influenced by human factors and natural factors such as wind. Another research [43] carried out in the Loess Plateau in China also indicated that the cumulative evapotranspiration by EC method and Lysimeter method was nearly the same though the dispersion degree of two daily evapotranspiration series was large. Qi et al. [37] found that evapotranspiration 


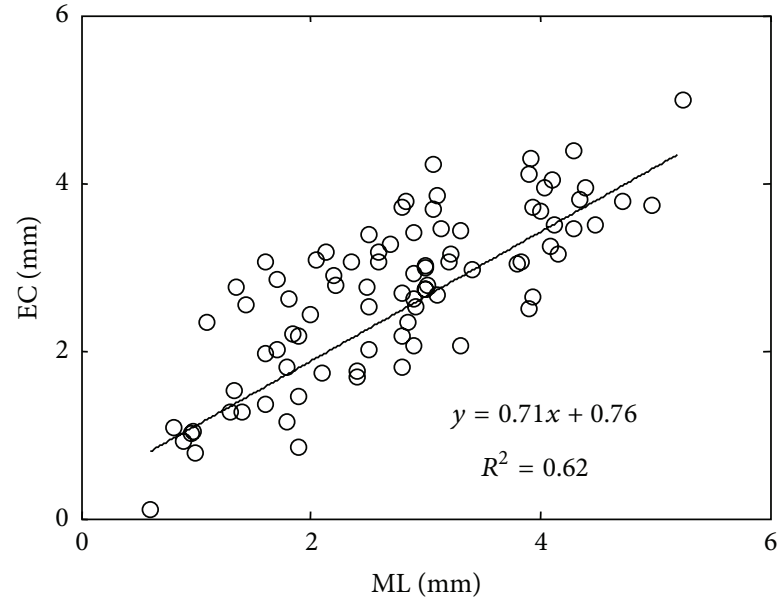

(a)

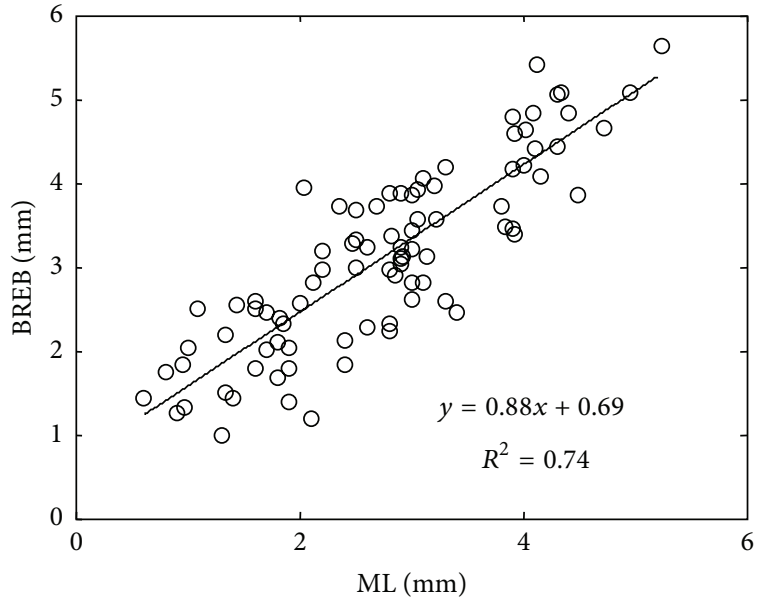

(b)

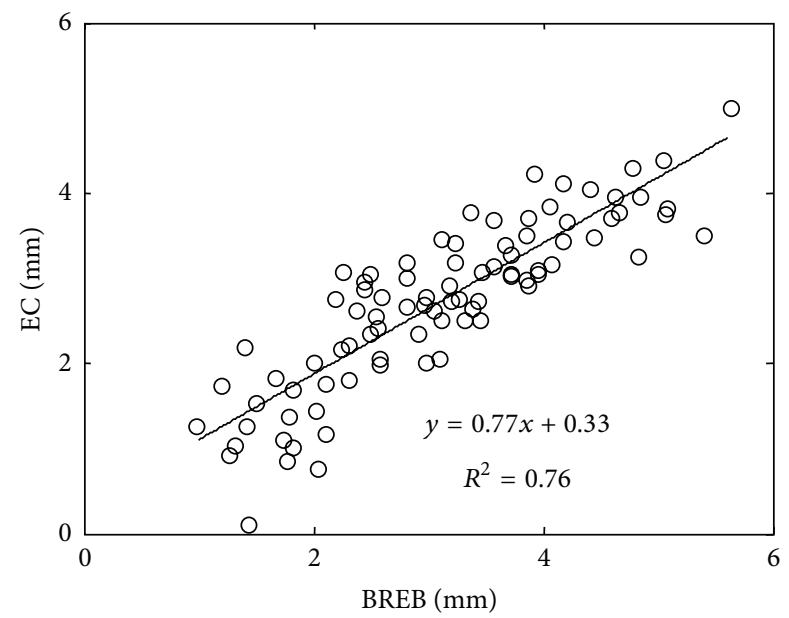

(c)

FIGURE 4: Relationship of evapotranspiration between EC, BREB, and ML.

measured by lysimeter $(148.7 \mathrm{~mm})$ was $19 \%$ larger than that estimated by the eddy covariance method $(125.4 \mathrm{~mm})$ in an alpine meadow in QTP.

The cumulative evapotranspiration by BREB method was $13 \%$ higher than that by ML method in this study. Qi et al. [37] reported that this percentage was $20 \%$ in an alpine meadow in QTP. The observational results in a soybean land indicated that the evapotranspiration by BREB method was basically the same as that by lysimeter measurements in case of nonadvection, while the former was a bit lower than the latter under advection conditions. Qiang et al. [44] found that the evapotranspiration by BREB method was consistent with that by lysimeter measurements in winter wheat field in an irrigation experiment station in northwestern China while Zhu [45] found that the evapotranspiration by BREB method was $20 \%$ lower than that by lysimeter measurements in a wheat field in eastern China. The differences between experimental conditions such as irrigation and atmospheric stratification may be the cause of different findings.

Evapotranspiration measured by eddy covariance system was lower than that estimated by BREB method in this area.
It was similar in many studies $[37,44,46]$. By using the data from 4 sets of BREB systems and 3 sets of EC systems in an irrigated spring wheat field, Dugas et al. [16] found that the latent heat flux was underestimated by EC systems and thus the evapotranspiration was underestimated. As discussed above, due to the special environmental conditions as well as the shortage of eddy covariance systems, the turbulent flux was underestimated which led to a lower evapotranspiration.

Evapotranspiration calculated by the BREB method was higher than that estimated by the other two methods. The main reasons for this may be listed as follows.

(1) Gradient Measurement Errors for BREB Method. As located in QTP, the observational site got larger solar radiation and wider air temperature variation range. What is more, more precipitation occurred in summer and led to higher soil water content. The atmosphere was in an unstable state and the vertical gradient of the vapor pressure was smaller during daytime. All those factors may lead to higher measurement errors for Bowen ratio system. Meanwhile, for the atmospheric layer was thinner and inverse solar radiation 
was smaller on the plateau, the cooling rate was larger at night and in the evening. This led to higher calculated latent and sensible heat fluxes.

(2) Error Caused by the BREB Basic Assumption. A basic assumption for BREB was that vapor turbulent exchange coefficient $\left(K_{w}\right)$ was equal to turbulent heat transfer coefficient $\left(K_{h}\right)$, that is, $K_{h}=K_{w}$. For underlying surface which was flat, uniform, and stable atmospheric stratification, $K_{h} \approx K_{w}$, the error for calculating the evapotranspiration using BREB method was relatively smaller. The air temperature varied violently in sunny days, the convection was obvious during daytime, and the atmosphere was often unstable. All those aspects made it very hard to meet the basic assumption for BREB in QTP.

(3) The Fluctuation of Bowen Ratio $\beta$. The atmospheric instability on the plateau determined the large fluctuations of Bowen ratio $\beta$ especially at sunrise (8:00-9:00 in growing season) and sunset (20:00-21:00 in growing season). In this case, the radiation balance and the atmospheric stability were at the negative/positive conversion moment. $\beta$ value varied around -1 ; LE calculated by BREB method had to be discarded.

5.3. The Uncertainty in Estimates of Actual Evapotranspiration. Uncertainty suggests a quantification of the precision of a measurement [47]. There is a growing recognition that more attention needs to be placed on quantifying the uncertainties inherent in the measurements of surface-atmosphere fluxes of carbon and energy at eddy covariance sites [48]. In general, uncertainty sources are classified as either systematic or random [49].

5.3.1. The Uncertainty Estimation of ML Method. Lysimeters make direct measurements; therefore a statistical uncertainty analysis should be considered. In this study, root mean square error (RMSE) was taken to evaluate the uncertainty of ML method. The uncertainty was calculated as

$$
\mathrm{RMSE}=\sqrt{\frac{1}{n} \sum_{i=1}^{n}\left(Z(s)-z\left(s_{i}\right)\right)^{2}},
$$

where $Z(s)$ is the average value; $z\left(s_{i}\right)$ is the observed value at sampling point $s_{i}$; and $n$ is the number of sample points.

We had 3 sets of micro-lysimeters for the measurement of ET at the experiment site. The results showed that the uncertainty was $15.6 \mathrm{~mm}$ at $95 \%$ confidence level.

5.3.2. The Uncertainty Estimation of BREB Method. Finkelstein and Sims [50] suggested that the random flux measurement error could be characterized if multiple independent observations were made in one place. Hollinger and Richardson [51] developed an alternative method (daily differencing approach) that would enable the estimation of the random uncertainty even when researchers had no second tower. Repeated sampling method [51] was used to calculate the random uncertainty of BREB method in this study. The random error was quantified in the measured values $\left(x_{1}, x_{2}\right)$ by determining $\sigma(\delta)$ :

$$
\sigma(\delta)=\frac{\sigma\left(x_{1}, x_{2}\right)}{\sqrt{ } 2},
$$

where $x_{1}$ and $x_{2}$ are two simultaneous measurements of the same quantity on two successive days and $\sigma\left(x_{1}, x_{2}\right)$ is the variance of the different measurements.

The estimated random uncertainty of RBEB method was $19.6 \mathrm{~mm}$ at $95 \%$ confidence level.

5.3.3. The Uncertainty Estimation of EC Method. Richardson and Hollinger [52] described a set of methods to quantify the uncertainties in annual net ecosystem exchange (NEE) that were due to both random measurement error and gap filling, including the additional uncertainty that could be attributed to long gaps. Here we used this method to estimate the uncertainty of EC method:

$$
\sigma_{T}(\mathrm{ET})=\sqrt{\sigma_{m}^{2}+\sigma_{g}^{2}}
$$

where $\sigma_{T}$ is the total uncertainty and $\sigma_{m}$ and $\sigma_{g}$ are measurement uncertainty and gap-filling uncertainty, respectively. The detailed calculation of $\sigma_{m}$ and $\sigma_{g}$ was described in Richardson and Hollinger [52].

The calculated total uncertainty of ET estimated by EC method was $15.1 \mathrm{~mm}$ at $95 \%$ confidence level.

\section{Conclusion}

Eddy covariance (EC) technique, Bowen ratio energy balance (BREB) method, and micro-lysimeter (ML) method were used to estimate actual evapotranspiration in alpine meadow in the northeastern edge of Qinghai-Tibet Plateau. The estimated daily results from 3 methods were in a good agreement. The cumulative evapotranspiration estimated by BREB method under no consideration of uncertainty was higher than that estimated by ML method and EC method.

There is still a certain degree of difficulty with accurate measurement of evapotranspiration. The uncertainties of evapotranspiration estimation were calculated by using different methods. Combined with precipitation data, soil moisture conditions, vegetation growth, and other natural conditions over the same period, the evapotranspiration can be determined roughly. During the beginning and end of the observation, the soil water content was nearly the same and no obvious soil water storage or water loss occurred. No surface runoff and no obvious leakage generated during the whole observation period. Furthermore, the vegetation grew well without any irrigation. It inferred that evapotranspiration should be roughly equal to precipitation which was $252 \mathrm{~mm}$ during the observation period. Considering the uncertainties, the cumulative evapotranspiration estimated by BREB method, ML method, and EC method was all within a reliable range.

Although evapotranspiration was likely to be underestimated by the eddy covariance method because of the inclosure of the energy balance, the evapotranspiration can 
be obtained directly through the latent heat flux from eddy covariance method. Also, long-term and continuous observations for the evapotranspiration in a certain area can be achieved by EC method and this made EC method one of the most important methods to estimate the evapotranspiration. Furthermore, EC method can also be used to determine the $\mathrm{CO}_{2}$ flux. It has more significance to be used in the grassland regions.

The cost for evapotranspiration by micro-lysimeter method was much lower compared to the other 2 methods. The measurement process was vulnerable to be influenced by manual or natural conditions. Also, heavy labor intensity was always needed. The most obvious disadvantage was that continuous observations were unable to realize by this method.

Compared to the eddy covariance method, Bowen ratio energy balance method had lower equipment costs. Though it usually had a high accuracy for estimating evapotranspiration, BREB method is being replaced by the eddy covariance method.

\section{Conflict of Interests}

The authors declare that there is no conflict of interests regarding the publication of this paper.

\section{Acknowledgments}

This research was conducted within the Projects of the National Natural Science Foundation of China (nos. 41130638, 41271085), National Scientific and Technological Support Project (2013BAB05B03), and open fund Project of State Key Laboratory of Cryospheric Science (SKLCSOP-2013-05). The authors are very grateful to the staff who worked in harsh environment for the field observations.

\section{References}

[1] A. Maruyama and T. Kuwagata, "Coupling land surface and crop growth models to estimate the effects of changes in the growing season on energy balance and water use of rice paddies," Agricultural and Forest Meteorology, vol. 150, no. 7-8, pp. 919-930, 2010.

[2] J.-K. Wu, Y.-J. Ding, G.-X. Wang, Y.-P. Shen, Y. Yusuke, and K. Jumpei, "Evapotranspiration of low-lying prairie wetland in middle reaches of heihe river in Northwest China," Chinese Geographical Science, vol. 15, no. 4, pp. 325-329, 2005.

[3] W. Zhao, X. Ji, and H. Liu, "Progresses in evapotranspiration research and prospect in desert oasis evapotranspiration research," Arid Zone Research, vol. 28, no. 3, pp. 463-470, 2011.

[4] S. E. Koch, A. Aksakal, and J. T. McQueen, "The Influence of Mesoscale Humidity and Evapotranspiration Fields on a Model Forecast of a Cold-Frontal Squall Line," Monthly Weather Review, vol. 125, no. 3, pp. 384-409, 1997.

[5] R. J. Donohue, M. L. Roderick, and T. R. McVicar, "On the importance of including vegetation dynamics in Budyko's hydrological model," Hydrology and Earth System Sciences, vol. 11, no. 2, pp. 983-995, 2007.
[6] N. Katerji and G. Rana, "Crop reference evapotranspiration: a discussion of the concept, analysis of the process and validation," Water Resources Management, vol. 25, no. 6, pp. 1581-1600, 2011.

[7] S. Trajkovic, "Testing hourly reference evapotranspiration approaches using lysimeter measurements in a semiarid climate," Hydrology Research, vol. 41, no. 1, pp. 38-49, 2010.

[8] R. C. Beeson Jr., "Weighing lysimeter systems for quantifying water use and studies of controlled water stress for crops grown in low bulk density substrates," Agricultural Water Management, vol. 98, no. 6, pp. 967-976, 2011.

[9] U. K. Schuch and D. W. Burger, "Water use and crop coefficients of woody ornamentals in containers," Journal of the American Society for Horticultural Science, vol. 122, no. 5, pp. 727-734, 1997.

[10] C. Liu, X. Zhang, and Y. Zhang, "Determination of daily evaporation and evapotranspiration of winter wheat and maize by large-scale weighing lysimeter and micro-lysimeter," Agricultural and Forest Meteorology, vol. 111, no. 2, pp. 109-120, 2002.

[11] M. G. McKeon, D. C. Joyce, and R. H. Frith, "A compact and inexpensive mobile weighing device for water relations studies of container-grown trees," Australian Journal of Botany, vol. 56, no. 6 , pp. 535-538, 2008.

[12] J. J. S. Owen, S. L. Warren, and T. E. Bilderback, "A gravimetric approach to real-time monitoring of substrate wetness in container grown nursery crops," Acta Horticulturae, vol. 819, pp. 317-324, 2009.

[13] Y. Wang, X. Wang, Q. Zheng, C. Li, and X. Guo, "A comparative study on hourly real evapotranspiration and potential evapotranspiration during different vegetation growth stages in the Zoige Wetland," Procedia Environmental Sciences, vol. 13, pp. 1585-1594, 2012

[14] V. R. N. Pauwels and R. Samson, "Comparison of different methods to measure and model actual evapotranspiration rates for a wet sloping grassland," Agricultural Water Management, vol. 82, no. 1-2, pp. 1-24, 2006.

[15] A. G. Barr, K. M. King, T. J. Gillespie, G. den Hartog, and H. H. Neumann, "A comparison of Bowen ratio and eddy correlation sensible and latent heat flux measurements above deciduous forest," Boundary-Layer Meteorology, vol. 71, no. 1-2, pp. 21-41, 1994.

[16] W. A. Dugas, L. J. Fritschen, L. W. Gay et al., "Bowen ratio, eddy correlation, and portable chamber measurements of sensible and latent heat flux over irrigated spring wheat," Agricultural and Forest Meteorology, vol. 56, no. 1-2, pp. 1-20, 1991.

[17] H. E. Unland, P. R. Houser, W. J. Shuttleworth, and Z.-L. Yang, "Surface flux measurement and modeling at a semi-arid Sonoran Desert site," Agricultural and Forest Meteorology, vol. 82, no. 1-4, pp. 119-153, 1996.

[18] T. E. Twine, W. P. Kustas, J. M. Norman et al., "Correcting eddycovariance flux underestimates over a grassland," Agricultural and Forest Meteorology, vol. 103, no. 3, pp. 279-300, 2000.

[19] T. Yao, L. Thompson, W. Yang et al., "Different glacier status with atmospheric circulations in Tibetan Plateau and surroundings," Nature Climate Change, vol. 2, no. 9, pp. 663-667, 2012.

[20] S. Zhou, P. Wu, C. Wang, and J. Han, "Spatial distribution of atmospheric water vapor and its relationship with precipitation in summer over the Tibetan Plateau," Acta Geographica Sinica, vol. 66, no. 11, pp. 1466-1478, 2011.

[21] X. Zhang and M. Yang, "Evapotranspiration in the tibetan plateau based on GAME-Tibet IOP data," Scientia Geographica Sinica, vol. 30, no. 6, pp. 929-935, 2010. 
[22] Y. Sheng, J. Li, J.-C. Wu, B.-S. Ye, and J. Wang, "Distribution patterns of permafrost in the upper area of Shule River with the application of GIS technique," Journal of China University of Mining and Technology, vol. 39, no. 1, pp. 32-39, 2010.

[23] W. Liu, S. Chen, X. Qin et al., "Storage, patterns, and control of soil organic carbon and nitrogen in the northeastern margin of the Qinghai-Tibetan Plateau," Environmental Research Letters, vol. 7, no. 3, Article ID 035401, 2012.

[24] X. Xie, G. J. Yang, Z.-R. Wang, and J. Wang, "Landscape pattern change in mountainous areas along an altitude gradient in the upper reaches of Shule River," Chinese Journal of Ecology, vol. 29, no. 7, pp. 1420-1426, 2010.

[25] S. Yi, Z. Zhou, S. Ren et al., "Effects of permafrost degradation on alpine grassland in a semi-arid basin on the Qinghai-Tibetan Plateau," Environmental Research Letters, vol. 6, no. 4, Article ID 045403, pp. 454-457, 2011.

[26] Y. Qin and S. Yi, "Diurnal characteristics of ecosystem respiration of alpine meadow on the Qinghai-Tibetan plateau: implications for carbon budget estimation," The Scientific World Journal, vol. 2013, Article ID 289754, 5 pages, 2013.

[27] X. Lee, W. J. Massman, and B. E. Law, Handbook of Micrometeorology: A Guide for Surface Flux Measurements, Kluwer Academic Publishers, Dordrecht, The Netherlands, 2004.

[28] D. Papale, M. Reichstein, M. Aubinet et al., "Towards a standardized processing of net ecosystem exchange measured with eddy covariance technique: algorithms and uncertainty estimation," Biogeosciences, vol. 3, no. 4, pp. 571-583, 2006.

[29] E. Falge, D. Baldocchi, R. Olson et al., "Gap filling strategies for defensible annual sums of net ecosystem exchange," Agricultural and Forest Meteorology, vol. 107, no. 1, pp. 43-69, 2001.

[30] S. B. Verma, D. D. Baldocchi, D. E. Anderson, D. R. Matt, and R. J. Clement, "Eddy fluxes of $\mathrm{CO}_{2}$, water vapor, and sensible heat over a deciduous forest," Boundary-Layer Meteorology, vol. 36, no. 1-2, pp. 71-91, 1986.

[31] L. Mahrt, "Flux sampling errors for aircraft and towers," Journal of Atmospheric and Oceanic Technology, vol. 15, no. 2, pp. 416429, 1998.

[32] E. L. Andreas and B. A. Cash, "A new formulation for the Bowen ratio over saturated surfaces," Journal of Applied Meteorology, vol. 35, no. 8, pp. 1279-1289, 1996.

[33] K. Wilson, A. Goldstein, E. Falge et al., "Energy balance closure at FLUXNET sites," Agricultural and Forest Meteorology, vol. 113, no. 1-4, pp. 223-243, 2002.

[34] Y. Ma and Z. Xu, "The physical characteristics of atmosphere in Qinghai-Tibet plateau," Acta Meteorologica Sinica, vol. 45, no. 2, pp. 210-217, 1987.

[35] H. J. H. Franssen, R. Stöckli, I. Lehner, E. Rotenberg, and S. I. Seneviratne, "Energy balance closure of eddy-covariance data: a multisite analysis for European FLUXNET stations," Agricultural and Forest Meteorology, vol. 150, no. 12, pp. 1553$1567,2010$.

[36] Z. Li, G. Yu, X. Wen, L. Zhang, C. Ren, and Y. Fu, "Energy balance closure at ChinaFLUX sites," Science in China, Series D: Earth Sciences, vol. 48, no. 1, pp. 51-62, 2005.

[37] P.-T. Qi, S. Gu, Y.-H. Tang, M.-Y. Du, L.-B. Wu, and L. Zhao, "Comparison of three methods for measurement of evapotranspiration in an alpine meadow," Acta Ecologica Sinica, vol. 28, no. 1, pp. 202-211, 2008.

[38] S. Gu, Y. Tang, X. Cui et al., "Energy exchange between the atmosphere and a meadow ecosystem on the Qinghai-Tibetan Plateau," Agricultural and Forest Meteorology, vol. 129, no. 3-4, pp. 175-185, 2005.
[39] Q. Li, X.-Z. Zhang, P.-L. Shi, Y.-T. He, L.-L. Xu, and W. Sun, "Study on the energy balance closure of alpine meadow on Tibetan Plateau," Journal of Natural Resources, vol. 23, no. 3, pp. 391-399, 2008.

[40] B. R. Reverter, A. Carrara, A. Fernández et al., "Adjustment of annual NEE and ET for the open-path IRGA self-heating correction: magnitude and approximation over a range of climate," Agricultural and Forest Meteorology, vol. 151, no. 12, pp. 1856-1861, 2011.

[41] G. G. Burba, D. K. McDermitt, A. Grelle, D. J. Anderson, and $\mathrm{L}$. $\mathrm{Xu}$, "Addressing the influence of instrument surface heat exchange on the measurements of $\mathrm{CO}_{2}$ flux from open-path gas analyzers," Global Change Biology, vol. 14, no. 8, pp. 1854-1876, 2008.

[42] X. Ji, W. Zhao, E. Kang et al., "Effect of the instrument surface heating on $\mathrm{CO}_{2}$ flux from open-path eddy covariance system at Linze Station," Plateau Meteorology, vol. 32, no. 1, pp. 65-77, 2013.

[43] Q. Zhang, Z. Zhang, X. Wen et al., "Comparisons of observational methods of land surface evapotranspiration and their influence factors," Advances in Earth Science, vol. 26, no. 5, pp. 538-547, 2011.

[44] X. Qiang, H. Cai, and J. Wang, "Comparative study of crop evapotranspiration measured by Bowen ratio and lysimeter," Transactions of the Chinese Society of Agricultural Engineering, vol. 25, no. 2, pp. 12-17, 2009.

[45] Z. Zhu, "Comparative study of crop evapotranspiration measured by Bowen ratio energy balance method and lysimeter," in Crop Evapotranspiration, D. Zuo and X. Xie, Eds., pp. 71-79, Meteorologic Press, Beijing, China, 1991.

[46] B. L. Blad and N. J. Rosenberg, "Lysimetric calibration of the Bowen ratio energy balance method for evapotranspiration estimation in the central great plains," Journal of Applied Meteorology, vol. 13, no. 2, pp. 227-236, 1974.

[47] D. P. Billesbach, "Estimating uncertainties in individual eddy covariance flux measurements: a comparison of methods and a proposed new method," Agricultural and Forest Meteorology, vol. 151, no. 3, pp. 394-405, 2011.

[48] A. D. Richardson, D. Y. Hollinger, G. G. Burba et al., "A multisite analysis of random error in tower-based measurements of carbon and energy fluxes," Agricultural and Forest Meteorology, vol. 136, no. 1-2, pp. 1-18, 2006.

[49] G. Lasslop, M. Reichstein, J. Kattge, and D. Papale, "Influences of observation errors in eddy flux data on inverse model parameter estimation," Biogeosciences, vol. 5, no. 5, pp. 13111324,2008 .

[50] P. L. Finkelstein and P. F. Sims, "Sampling error in eddy correlation flux measurements," Journal of Geophysical Research D: Atmospheres, vol. 106, no. 4, pp. 3503-3509, 2001.

[51] D. Y. Hollinger and A. D. Richardson, "Uncertainty in eddy covariance measurements and its application to physiological models," Tree Physiology, vol. 25, no. 7, pp. 873-885, 2005.

[52] A. D. Richardson and D. Y. Hollinger, "A method to estimate the additional uncertainty in gap-filled NEE resulting from long gaps in the $\mathrm{CO}_{2}$ flux record," Agricultural and Forest Meteorology, vol. 147, no. 3-4, pp. 199-208, 2007. 

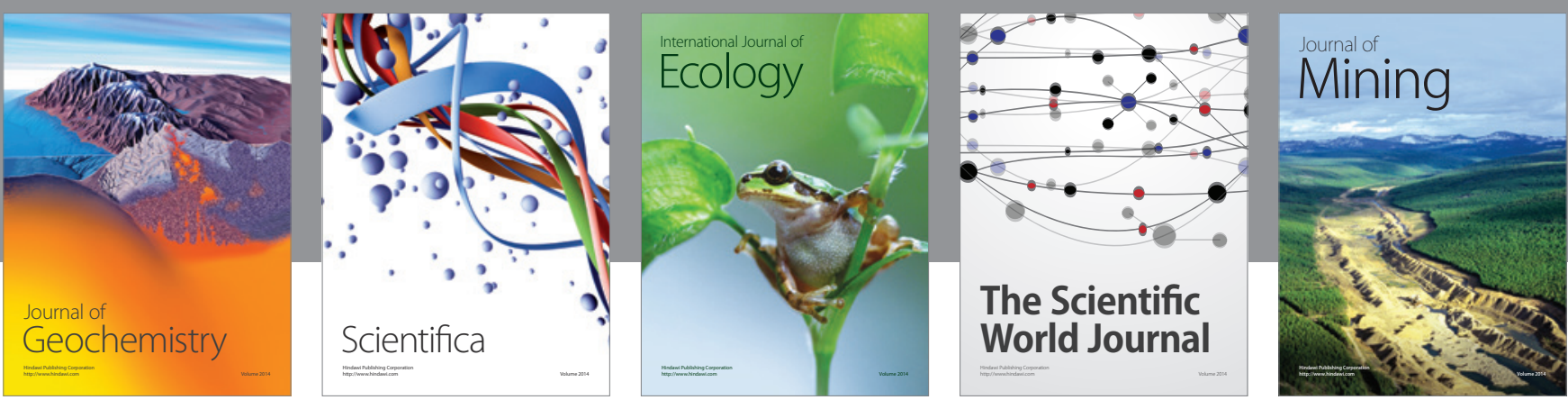

The Scientific World Journal
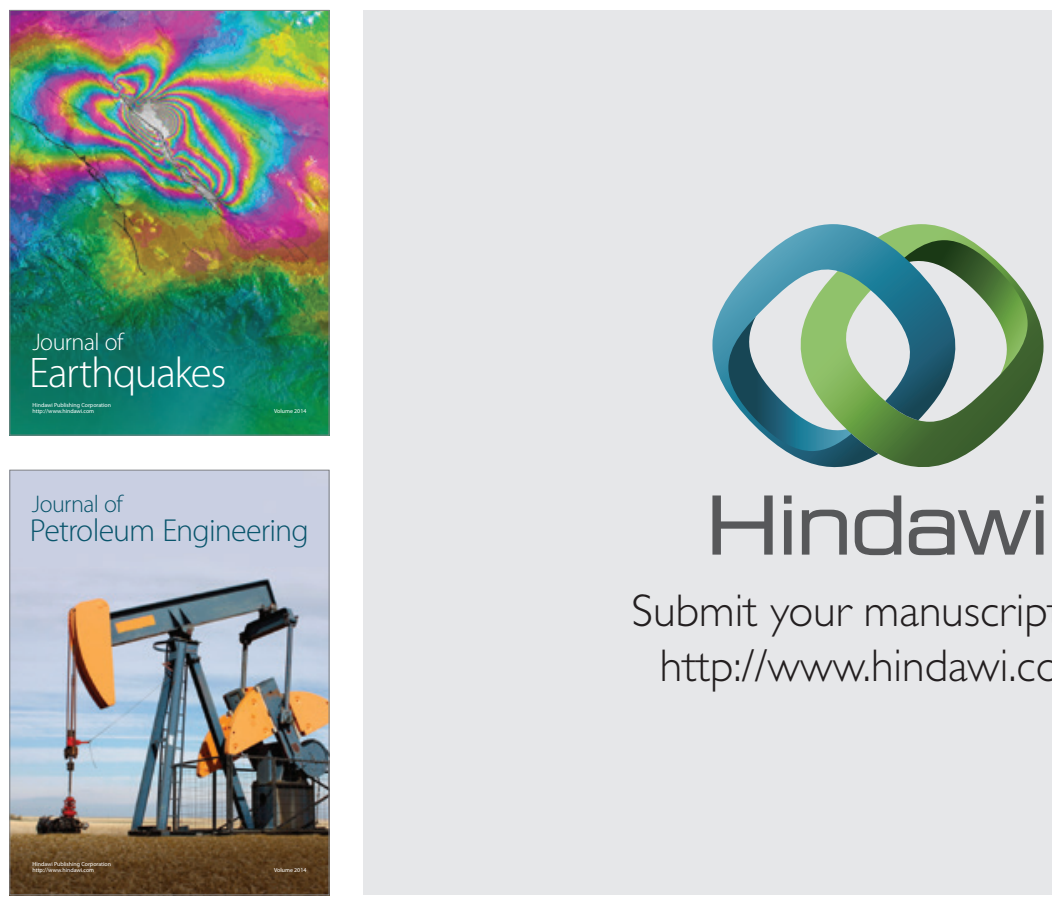

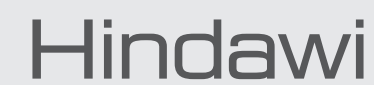

Submit your manuscripts at

http://www.hindawi.com
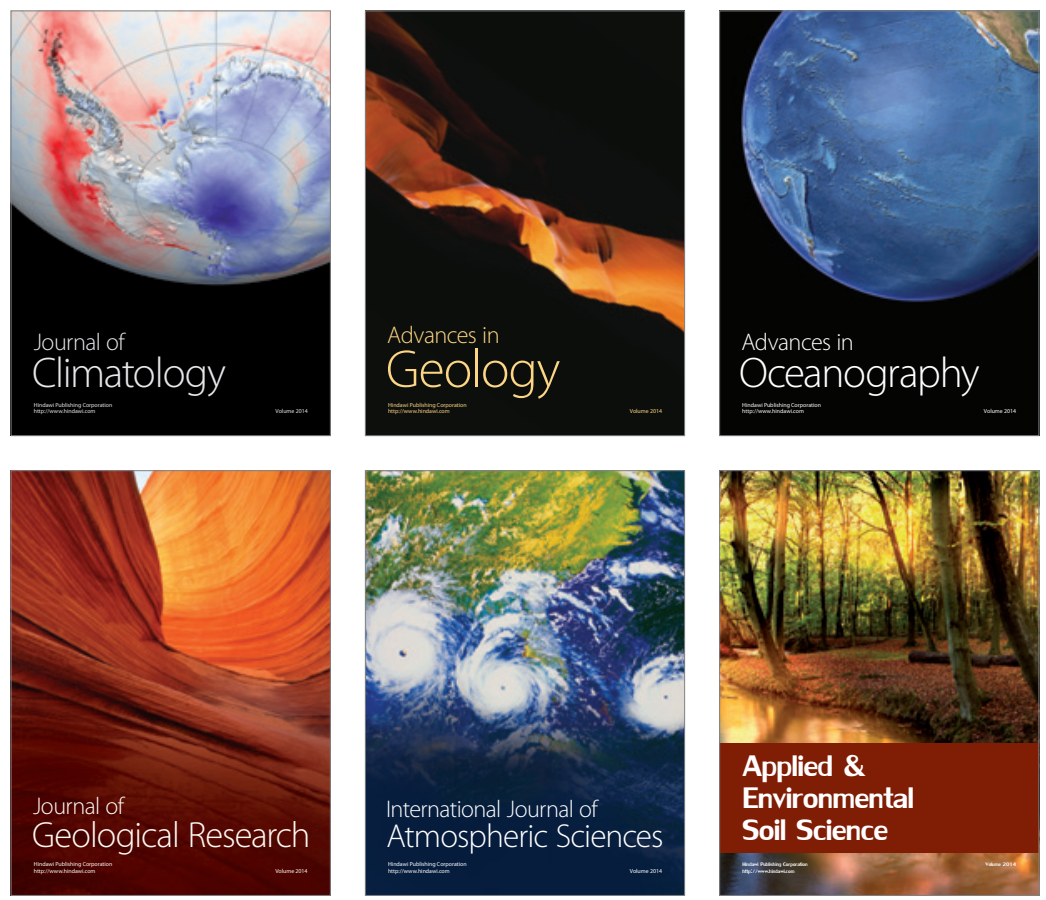
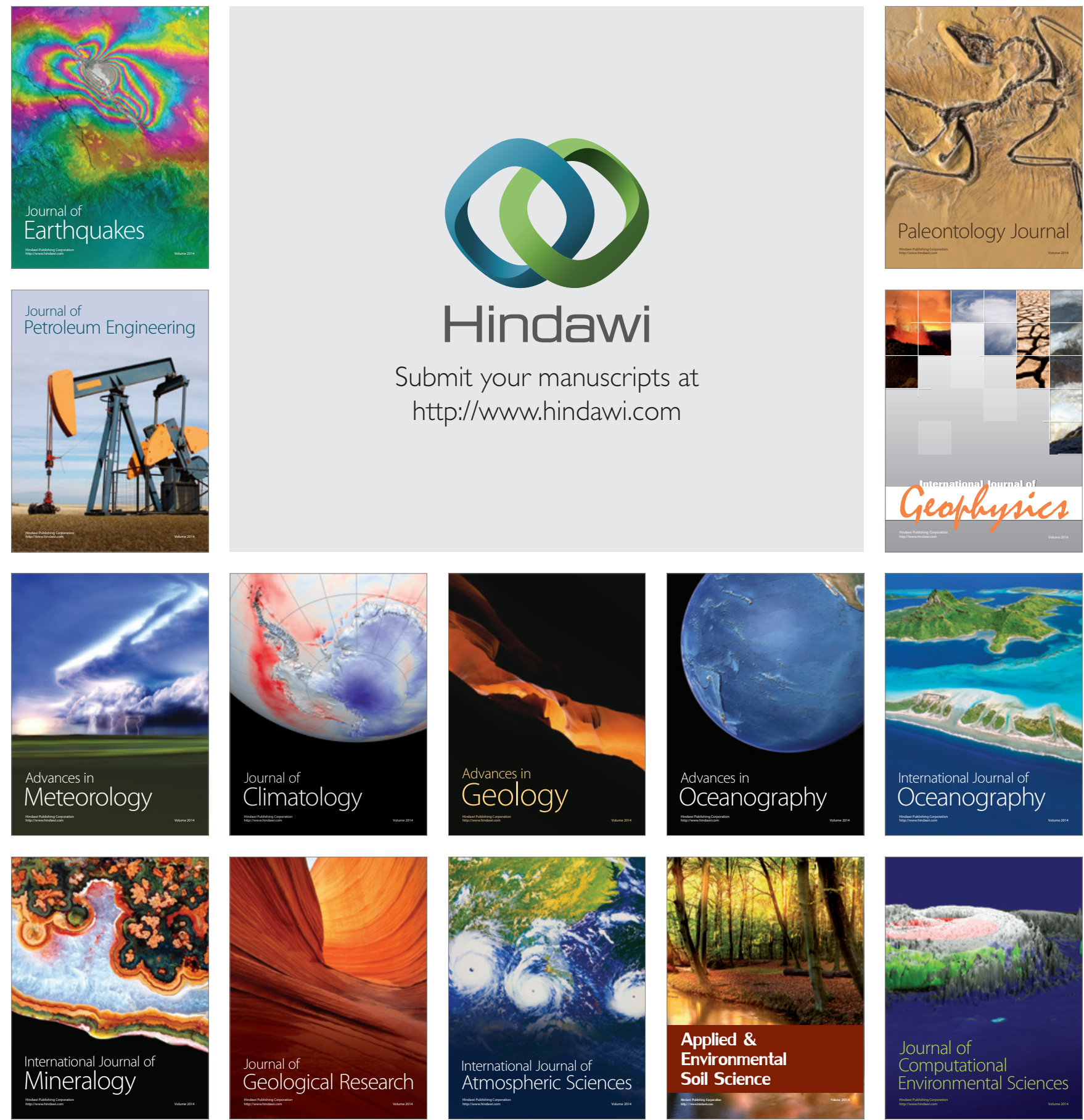